\title{
ANTIOXIDANTES EM ALIMENTOS: INFORMAÇÕES ROTULARES
}

\author{
Vânia Thais Silva Gomes ${ }^{1}$ \\ Raimundo Silva Gomes ${ }^{2}$ \\ Maria Silva Gomes ${ }^{3}$ \\ Larissa Vanessa Machado Viana ${ }^{4}$ \\ Francileine Rodrigues da Conceição ${ }^{5}$ \\ Laís Mayara Machado de Amorim ${ }^{6}$ \\ Patrícia de Souza Genaro ${ }^{7}$
}

Resumo: Neste trabalho foram avaliados dez tipos de alimentos industrializados na cidade de Caxias-MA, sendo analisadas três unidades de cada tipo de alimento, com a finalidade de identificar nos rótulos dos respectivos alimentos os antioxidantes neles presentes e classificá-los pela sua funcionalidade, verificou-se também as RDC's quanto esse tipo de informação. Foram identificados treze tipos de antioxidantes, destes, cinco estavam em desacordo com a RDC 259/02 por não apresentarem seus nomes completos ou não estavam lista de ingredientes. Em dois tipos de alimentos nenhum antioxidante foi relacionado. Portanto torna-se evidente a necessidade deste tipo de informação para prevenção e manutenção da saúde da população.

Palavras-chave: Antioxidantes; Rótulos; Aditivos; Alimentos industrializados.

\footnotetext{
1 Doutoranda em Engenharia Biomédica/Instituto de Pesquisa e Desenvolvimento/UNIVAP, Brasil. E-mail: vaniathais02@hotmail.com.

2 Doutorando em Engenharia Biomédica/Instituto de Pesquisa e Desenvolvimento/UNIVAP, Brasil. E-mail: raigomezz19@hotmail.com.

3 Assistente Social/ Faculdade de Ciências e Tecnológica do Maranhão, Brasil. E-mail: assistente.socialmaria23@gmail.com.

4 Mestranda em Engenharia Biomédica/Instituto de Pesquisa e Desenvolvimento/UNIVAP, Brasil. E-mail: laris_machado@hotmail.com.

5 Nutricionista/Faculdade de Ciências e Tecnologia do Maranhão- FACEMA, Brasil. E-mail: wirnamarilia@hotmail.com.

6 Mestranda em Engenharia Biomédica/Instituto de Pesquisa e Desenvolvimento/UNIVAP, Brasil. E-mail: lais_mayara@hotmail.com.

${ }^{7}$ Doutora em Saúde Pública/Universidade do Vale do Paraíba, Brasil. E-mail: psgenaro@gmail.com.
} 